\title{
Strategy for Improving Effectiveness of Green Open Space Management Through Tree Identity Application
}

\author{
Dewi Gartika ${ }^{1}$ \\ \{d_gartika@yahoo.com ${ }^{1}$ \} \\ ${ }^{1}$ Research and Development Agency of West Java Province of Indonesia
}

\begin{abstract}
Utilization of information technology in the management of green open space (GOS) generally only see the width of land cover and its spread. In fact, in the management and monitoring of GOS, often found incidents that cause damage to GOS due to disaster or human. Research conducted in 2015 on the management and supervision of GOS in the Bandung City. The results showed that the Tree Identity Application (TIA) that has been owned by Bandung can not be used. The data should be used as a basis for action in the preparation of the GOS development plan as well as oversight of GOS. The cause factor is the absence of operators who operate the application and the absence of tree health data. As a result, during a rainstorm, trees that have been damaged due to disease or community behaviorcan not be anticipated by the government. The licensing mechanism for logging is done manually and not integrated with TIA. As a result, many healthy trees have been cut down. Finally, the researcher recommends that the TIA be equipped with tree health data, and the mechanism of tree felling permits online and the provision of specialized operators.
\end{abstract}

Keywords: Application, Tree Identity, Green Open Space Management

\section{Preliminary}

Population growth rate has encouraged land conversion due to physical development needed by the community to support their life needs. Not only houses, but offices, shopping centre, roads, harbour and other transportation are also needed by the community. The high rate of land function transformation causes the green open space (GOS) is getting less. In principle, GOS is part of an open space of an area filled with plants and crop to support ecological, social, cultural, economic and aesthetic benefits.

The presence of GOS in urban areas is very important as a balancing of life considering that urban area main activity is non-agricultural with area arrangements function as urban settlement place, concentration and distribution of government service, social service and economic activity(Anon, 2007). The decline in the quantity and quality of green open space in urban areas results urban environmental declining quality such as the frequent flooding in urban areas, high air pollution, and increased social vulnerability (crime and social crisis), decreased public productivity due to stress due to the limited public space available for social interaction and etc. In other words, the presence of GOS can control and maintain environment integrity and quality, because the presence of GOS has great benefits for balance, continuity, health, sustainability, and improving the quality of the environment itself.

West Java Province is one of provinces in Indonesia where the speed of development and conversion of land is very high. This is due to the population growth rate is very high so a larger space is required. The research results showed that the green open space problem in West Java's province cities/districts consists of: 1) Rapid urban development, resulting in 
many conversion of land function from agricultural cultivation area into residential area; 2) Most private GOS on urban farming have already converted to become constructed land (commercial); 3) River border in the planning area is almost entirely become developed area; 4) Communities less aware and concerned about the importance of GOS; 5) GOS under highvoltage electrical networks are not yet fully acquired, so they are still widely used for nongreen open space; 6) GOS handling that has not been done maximally by involving private sector and community; 7) The existence of an open parking lot is not accompanied by reforestation / tree planting, thus include as open space criteria only; 8) The existence of economic actors / street vendors around the city park area causing disruption of existing plants or vegetation; 9) Private GOS, especially for the housing yard is still lacking, it's seen from most of houses spent the entire lots to build a house so it does not have yard; 10) There has been no firm action by the authorities for trespasser or destroyers of existing GOS space; and 11) Lack of socialization on GOS by related institutions to community, causing many private GOS that are not in accordance with the prevailing regulations (Astriani, 2014).

Seeing the rapid development of land conversion progress, the Earth Summit in Rio de Janeiro in Brazil in 1992 and the Johanesburg Summit in South Africa in 2002, agreed that an ideal city should have a minimum of $30 \%$ of the total GOS (Astriani, 2014). Based on this, the government then issued Minister of Home Affairs Regulation No. 1 of 2007 on the Setup of Green Open Space Urban Area that regulate the arrangement of GOS, especially in urban areas (GOSUA) which includes planning, utilization, and control activities. In the GOSUA development planning activities sets about the type, location, area, area achievement target, cost requirements, implementation time target, and technical design. The ideal area of GOSUA is at least $20 \%$ of the total urban area that includes public GOSUA and private GOSUA. Furthermore, in the utilization of GOSUA activities explained that the utilization of GOSUA covers new development, maintenance, and security of green open space activities. In chapter 12 verse (3) it is stipulated that in order to securing GOSUA, public GOSUA managed by local government cannot be converted. Similarly to the GOSUA control activities, it is asserted that tree logging in public GOSUA areas is strictly limited and should be permitted by the head regional. The regulation also describes the scope of the GOSUA control which includes: a) Minimum area target achievement; b) Functions and benefits; c) Area and location; and d) Conformity of construction specifications with technical design. Control of GOSUA is done through licensing, monitoring, reporting and controlling(Anon, 2007). Thus, we can conclude that local governments are not only obliged to provide public GOSUA, but also to implement maintenance, monitoring, security, control of GOSUA.

However in its implementation, local governments have not been fully able to monitor, secure and control GOSUA optimally. Often found several events that potentially lead to the occurrence of green space damage, even causing the area of GOS to be reduced, for example the number of fallen trees caused by rain storms, trees that are deliberately damaged by the community for a particular interest or trees felled illegally by the community. If we analyse more profound, these events not only cause ecological losses, but also cause economic losses. Ecologically, the number of fallen/deliberated trees causes the occurrence of microclimate changes in the surrounding environment, because no more trees can provide shade, produce oxygen, absorb dust and other pollutant particles. Moreover, the fallen / felled trees causing economic losses, because to plant, maintain and raise a tree require a big cost. Although the pieces of the tree can be sold, but the price offered is not commensurate with the ecological benefits generated by the tree. Such events often occur, although government oversight is always enhanced. 
Based on this, researchers need to assess what instruments should be developed so that the effectiveness of GOSUA management and supervision can be improved so that we do not have to lose GOSUA due to disaster and community behaviour that deliberately damage GOSUA.

\section{Research Methods}

Research conducted in 2015 on the management of GOSUA implemented by the Government of Bandung City. The research was conducted by using qualitative method to dig deeper about GOSUA management in Bandung City. Data types used include primary data and secondary data. The primary data collection technique is conducted through interviews with informants who are considered the most aware about the management of GOSUA in Bandung City. While the secondary data obtained through data analysis study literature done by descriptive analysis to provide an overview of the real conditions and the preparation of policy recommendations to improve effectiveness of GOS management in the city of Bandung.

\section{Results and Discussion}

\subsection{The Concept of GOS Management}

Urban management can be described as a set of activities that together shape and direct the social, physical and economic development of the city (Hakim, (2008) inHamrun dan Prianto, 2007)). The management of green open spaces will give an impact on quality and quantity change, as described in Halle's research indicating that it is not easy to improve urban institutional strategies and have measurable output. There are several aspects of GOS management (Hakim, (2008) in Hamrun dan Prianto, 2007) i.e. planning, institutional, human resources, coordination and funding.

In the Minister of Home Affairs Regulation No. 1 year 2007 about setup of Green Open Space in Urban Area (GOSUA) has been explained that local governments have an obligation to provide public GOSUA and carry out maintenance, monitoring, security and control of GOSUA on their territory. As a public asset, the management of GOSUA must follow Good Governance principles. According to Wahab (in Tangkilisan, (2005) in Faisah \& Prianto, 2015). Good Governance is a concept in the management that solid and responsible that in line with democracy and efficient market, avoidance of misallocation and scarce investment and prevention of corruption both politically or administratively, running the budget discipline and the creation of legal and political framework for the growth of entrepreneurship activity. United Nations Development Program (UNDP) argues that principles developed in good governance are: a) Participation; b) Rule of law; and c) Transparency. Transparency must be built within the freedom framework of various information flow processes, institutions must be freely accessible by those who need, and information should be provided adequately and easily understood, so able to use as a monitoring and evaluation tool (Faisah \& Prianto, 2015).

Based on these, the management of GOSUA should be transparent. Utilization of Information Technology becomes very crucial in the management of GOSUA so that various data related GOSUA can be accessed easily as the basis of GOSUA management policy formulation, whether it is supervision, controlling, giving sanction for destruction of GOSUA, granting of logging license and rewarding for society which active in the provision and management of GOSUA.

\subsection{Management of GOSUA inBandung}


Bandung city is one of the most advanced cities in Indonesia, with an area of $16.729,65$ Ha, In 2015 the Government of Bandung City targets GOSUA area reach $12,15 \%$ means 2.032,21 Hacontained in the Mid Term Development Plan of Bandung Year 2013-2018. In the process of planning the provision of GOSUA, the Government of Bandung City preparing the GOS Masterplan in which there is data of existing green space and the potential for the GOS provision in Bandung City based on the needs of space and population distribution. The data are taken based on monitoring results conducted through GIS. Furthermore, to improve the management and supervision of GOS in the Bandung City, in 2014 Bandung City Government already has an application that provides information data about tree, which includes the name of tree species, the location of trees and number of trees. This application is similar to a Tree Identity. Based on the available information, the data can be used as a basis for action in the preparation of GOS development planning and monitoring of GOS.

However, in its implementation, one year after the application was made (in 2015) the application of Tree Identity was not used. One of the factors that become obstacles is the absence of operators to specifically operate the application. In the development, the application can only be accessed by the Head of Department of Funeral and Garden City of Bandung and Head of Green Open Space Bandung City. With a very high level of activity, both officials have limited time to access and operationalize the application. As a result, during the year 2015 the application is not used in monitoring trees on Bandung City in real time.

On the other hand, the data contained in this application can not be used in the maintenance and monitoring of the condition of trees In this application there is no data of health condition of tree. Information about age-related trees, health conditions and tree species are important information needed as a basis for tree maintenance programs located at GOSUA. During this time the maintenance of trees and other green space is only done through pruning, weeding, watering and fertilizing. For a sick tree, there is no curative action. Yet when the sick tree is left and eventually collapsed, it will endanger the road users. The absence of tree health data causes the local government cannot anticipate the fallen trees incident due to old age or damaged by disease or behaviour of the community.

Duryat et al (2014 in Sitinjak, 2016) explains that identification of tree health status is an important effort in tree management, in accordance with silvicultural principles to maintain the health of forest trees by controlling, facilitating, protecting and saving (salvaging). Measures to be taken in the care / handling of trees identified by the disease may be based on this data.

Trees are said to be healthy or normal is when the tree can still perform its physiological functions. Conversely, it is said unhealthy if the tree structurally damaged, either whole or part of the tree. The main causes of plant diseases can be pathogenic living organisms or physical environmental factors (Karlinasari et al., 2010 in Sitinjak, 2016).

In addition to pathogenic factors as one of the causes of tree damage, insect attacks, air pollution, human activities and biological factors and increasing tree age are thought to play a role in reducing the quality of trees. Decrease in the quality of this tree can be known through the level of damage suffered by the tree. According to Djafaruddin (1996 in Sitinjak, 2016), naturally included as disturbances plant can be grouped into: a) Disruptors including living organisms, such as pests, weeds and insects; b) Disruptors which not living bodies, for example natural disasters such as floods, erosion, drought, landslides caused by factors and elements of climate and weather are indirect factors that indirectly as a result of less sensitive to nature. Another element that affects tree damage is mechanical damage. Mechanical damage to trees can occur due to the fall of a tree causing injuries to the skin and wood, the 
fire on trees, hail or snow causing leaves and lightning strikes (Soeratmo, 1974 in Sitinjak, 2016).

Not only health data of tree, in the application should also be equipped with type of tree planted data in a particular area. In development planning activities GOSUA should consider the type of plant, location, and technical design (Anon, 2007). However, data types of trees contained in the application has not been used as a basis for planning the planting of certain tree species in a region. The type of tree to be planted should ideally refer to ecological and social needs, for example at heavy traffic areas where level of pollution is very high, then type of tree grown in that area should be capable for absorbing $\mathrm{CO}_{2}$, lead, dust and other particles, while for the public/social space, the planted plants should not be toxic or harmful to the community. Thus, this application is also used as a monitoring and evaluation tool, whether the planted tree has been in accordance with ecological needs or just to fulfil aesthetic function. Chiara and Lee E. Koppelman, (1997, in Rochim \& Syahbana, 2013) state that vegetation types and patterns are recreational, visual and ecological resources. Plant species selection that fit the criteria of planting can affect the function of green open space, for example in its ability to suppress air pollution, absorb dust, reduce odors, reduce noise, reduce soil erosion, rain and wind breaker as a whole. Guidelines for GOS development in urban areas, asserting that to improve life quality in urban areas including land, water, space and property contained therein, requires GOS maintenance and development (Krisdianto, et al. (2012) in Lestari et al., 2013). As part of the GOS, vegetation is very useful in modifying urban environments quality, which is an aesthetic improvement, erosion control, groundwater conservation, air and noise pollution, improving urban environmental comfort, wastewater control and stink (Ferry Andriono, et al. (2013) in Lestari et al., 2013).

Another part of the GOS control is the submission of permits and granting of logging permits proposed by the community for some reason, for example to extend access to their homes entrance or due to the age of old trees and feared to be uprooted. Regulation of the Minister of Home Affairs No. 1 of 2007 on Green Open Space Arrangement The Urban Area asserts that the arrangement of green open space especially in urban areas (GOSUA) includes planning, utilization and control activities. The control of GOSUA is done through licensing, monitoring, reporting and controlling. Felling of trees in public GOSUA areas is strictly restricted and must be permitted by the regional head (Anon, 2007). At this time, the mechanism of submission of permits and granting of logging licenses is still done manually and not yet integrated in Tree Identity Application. The absence of detailed and accurate tree data poses difficulties in granting permits, as it may be that the tree to be harvested is a health tree. Logging health trees will certainly cause losses, both ecologically and economically.In principle, the existence of tree health data in Tree Identification Application will make it easier for local governments to develop maintenance and supervision plans for vulnerable fallen trees and as a control tool in issuing tree cut permits for the general public.

\section{Conclusions}

In the Minister Of Home Affairs Regulation No. 1 of 2007 on the setup of green open space in urban area (GOSUA) has been explained that local governments have an obligation to provide public GOSUA and carry out maintenance, monitoring, security and control of GOSUA on their territory. As a public asset, the management of GOSUA must follow the principles of good governance, i.e. : a) participation; b) rule of law; and c) transparency. Therefore, the management of GOSUA must be done transparently. Utilization of information technology becomes very crucial in the management of GOSUA so that various data related 
GOSUA can be accessed easily as the basis of GOSUA management policy formulation, whether it is supervision, controlling, giving sanction for destruction of GOSUA, granting of logging license and rewarding for society which active in the provision and management of GOSUA. Application development of Tree Identity owned by the Government of Bandung City cannot be implemented properly. This is due to: a) the absence of operators to specifically operate the application; b) the absence of data regarding the health condition of the trees. Information about age-related trees, health conditions and tree species are important information needed as a basis for tree maintenance programs located at GOSUA. The absence of tree health data has prevented local governments from anticipating fallen trees from old age or damaged by disease or community behaviour; c) the data of tree species contained in the application has not been utilized as the basis for planning the planting of certain tree species in a region. Type of tree to be planted should ideally refer to ecological and social needs; and d) the mechanism for submission of permits and granting of logging permits has not been integrated in Tree IdentityApplication. The absence of detailed and accurate tree data poses difficulty in granting permits. Therefore, to optimize the utilization of information technology in the management of GOS in Bandung City, it is necessary to improve the application of Tree Identity owned by the Government of Bandung City by adding tree health data, data analysis of tree species in a particular area /path and equipped with the mechanism of submission logging trees online and operationalized by specialized operators.

\section{References}

[1] Astriani, N. (2014) 'Implication of Green Open Space Policy In Spatial Planning In West Java', Fiat Justicia Jurnal of Law Science, 8(2), pp. 242-254.

[2] Faisah, N. and Prianto, A. L. (2015) 'Good Environmental Governance (Case Study of Tiger Garden Management in Makassar City)', Otority Journal of Governmental Science, V(2), pp. 174-188.

[3] Hamrun dan Prianto, A. L. (2007) 'Green Open Space Management Policy in Makassar City’, in Proceedings of the National Seminar Prodi Science Governance UNIKOM. Prodi Ilmu Pemerintahan FISIP UNIKOM, pp. 674-695.

[4] Lestari, I., Yanuwiadi, B. and Soemarno (2013) 'Suitability Analysis of Green Open Space ( Gos ) Model Based On Area Characteristics in Kupang City , Indonesia', The International Journal Of Engineering and Science, 2(6), pp. 81-91.

[5] Regulation of the Minister of Home Affairs No.1 of 2007 on tehe Setup of Green Open Space Urban Area (2007).

[6] Rochim, F. N. R. and Syahbana, J. A. (2013) 'Stipulation of Function and Suitability of Vegetation in Public Garden as Green Open Space in Pekalongan City', Journal of Engineering PWK, 2(3), pp. 314-327.

[7] Sitinjak, E. V. (2016) Status KeHealth Status Of The Tree On The Green Line And Page Parking Of The University Of Lampung Lampung. University of Lampung. 